\title{
Low Power Polysilicon Sources for IR Applications
}

\author{
N.C. Das a, M. Shabvalab, and P. Shu \\ a Raytheon/STX, 4400 Forbes Blvd, Lanham, MD 20706, USA \\ ${ }^{b}$ Solid State Device branch, NASA/GSFC, Greenbelt, MD 20771, USA
}

\begin{abstract}
We have designed and fabricated polysilicon thin film infrared (IR) sources by micromachining technology. These sources are made with a lightly doped middle region for light emission and heavy doping of the supporting legs. The sources are fabricated on a $10 \mathrm{~mm}$ thick, low temperature silicon dioxide layer. Different doping levels were used to achieve various source resistances. From the power requirement to reach the required light emission versus source resistance curve it is seen that there exists a resistance value which minimizes the necessary input power.
\end{abstract}

\section{INTRODUCTION:}

Incandescent light sources have many applications. They are used in wideband spectral analysis of chemicals. Other potential uses are in infrared scene generation and calibration of photodetectors. Typically, the light emission from these sources ranges from the visible to far infrared region.

The conventional infrared calibration source [1] are made using tungsten filament suspended from a glass substrate. They have disadvantages such as; they require high input power, delicate handling, they are expensive and have low maximum operating temperature. Recently, [2], [3] miniature light sources have been fabricated using polysilicon thin film resistors. The resistors are heated by applying current to make the source glow in desired wavelength regions. These sources can glow in air or vacuum however the power requirement is far less in vacuum and the lifetime in ambient is severely reduced due to oxidation. Mastrangelo et al [4] reported the fabrication of vacuum sealed polysilicon filaments using IC technology. However. such types of sources are no longer produced. We have undertaken the development of polysilicon IR sources for the NASA Space Infrared Test Facility (SIRTF) flight project. These devices are to be used as the calibration sources for the focal plane infrared detectors. The requirements from this project are low power, long lasting, stable, and reliable sources. We designed various types of structures and used different process parameters in the fabrication of these sources. In this paper we describe the fabrication process and test results of low power polysilicon sources capable of operating at liquid helium temperature $(4.2 \mathrm{~K})$.

\section{FABRICATION OF POLYSILICON IR SOURCES:}

The fabrication process of the polysilicon sources starts with deposition of a $10.0 \mathrm{~mm}$ thick low temperature oxide (LTO) on a silicon substrate. A thick oxide layer is required to ensure that the polysilicon film will not touch the silicon substrate when the LTO is removed from underneath the structured for the bridge fabrication. Undoped polysilicon of $1.0 \mathrm{~mm}$ thickness was deposited by LPCVD method followed by a low dose blanket implantation on the polysilicon film. This low dose implant is critical as it determines the resistance of light emitting region. In our experiments we varied this implant dose to tailor the IR source resistor value. After the first implant, the polysilicon film was patterned and etched to form the resistor strip. Then a heavy dose boron implant $(2 \mathrm{E} / 6 / \mathrm{cm} 2)$ was carried out with the photoresist as the masking material in the light emitting region. Implantation is followed by a high temperature anneal. Aluminum metallization was carried out after contact windows were opened. Aluminum was patterned and etched from all the areas except the contact areas. Finally, a long oxide etch in buffered HF was carried to remove the oxide from the exposed area of the wafer and under the bridges. The fabrication process is completed by alloying at $490 \mathrm{C}$ for $20 \mathrm{~min}$. 


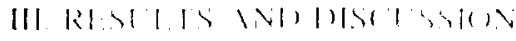

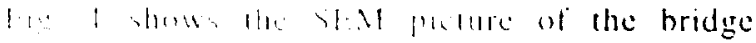

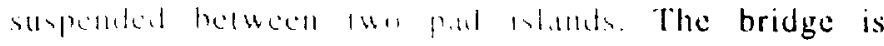

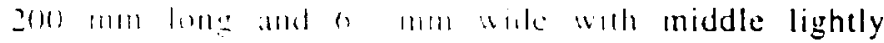

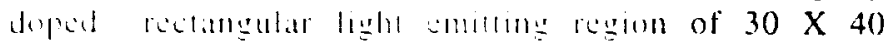
mm. It a clearly cent that the bridge bends downwards. The ligh cmollmg region is at lower than the supporting pulvillcun pad islands which are on the $10.0 \mu \mathrm{m}$ thick nxilk layer. Fig.2 shows the magnified view of the light emitting middle rectangular 1.30X+1) $\mu m$, region. The picture is the edge-on view of the source. The source is approximately 6.0 $\mu \mathrm{m}$ above the silicon surface. In order to get the light emission. the bridge has to be completely unatatched from the underneath silicon dioxide layer. A long oxide etch in buffered $H F$ is required for complet removal of silicon dioxide.

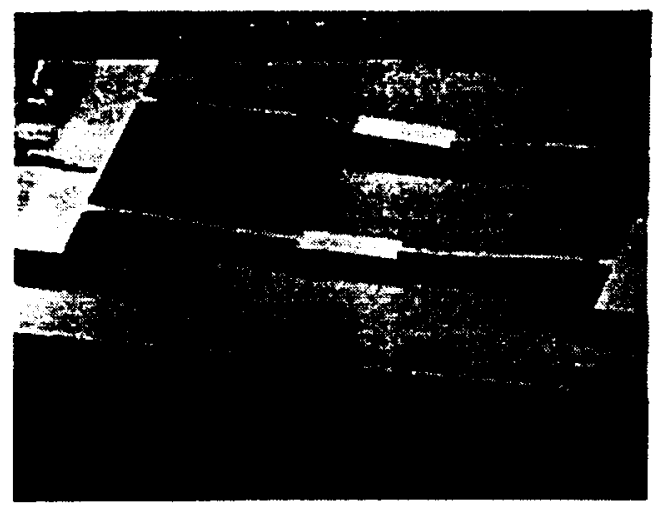

Figure 1. SEM of bridge hanging by two islands of low temperature oxide

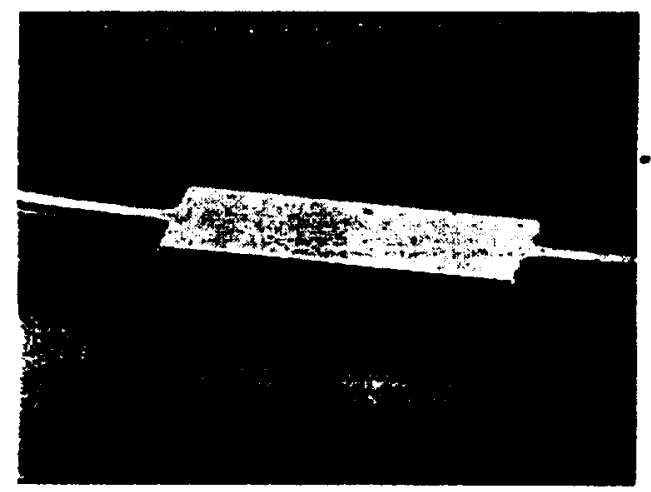

Figure 2. SEM of hridge portion where light emustinn accurs
The polysilicon sources are wire honded inte a TO.5 header. The $I-V$ curve were generaled while the sources are in valcuum. The valcuum chamber has a glass window through which the light emission was observed. The polysilicon sources behaves as a linear resistor for low bias values. As seen in Fig. 3, as the applied voltage is increased a saturation characteristic in the I-V curve is seen. This is followed by a non-linear increase of current with applied voltage. Our results agree with

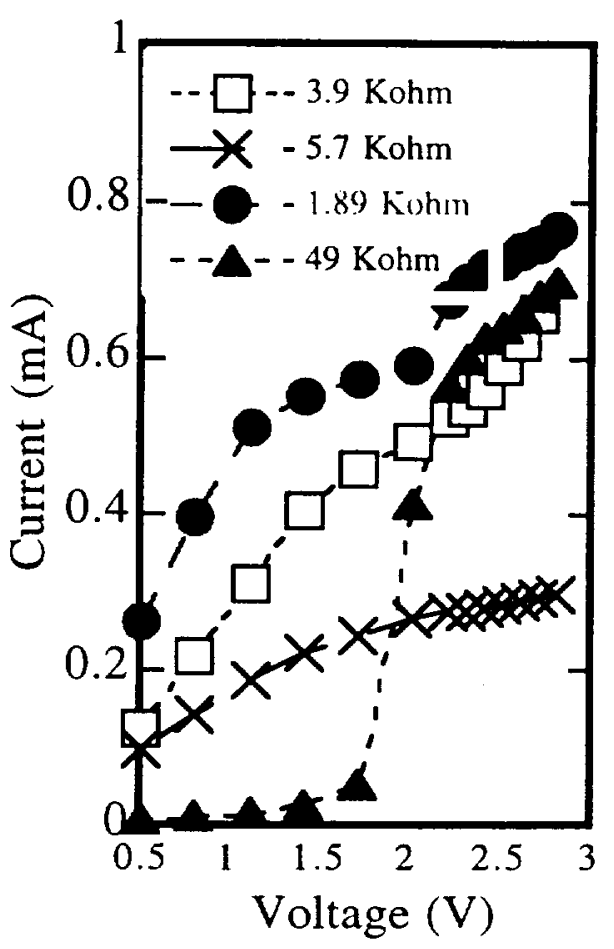

Figure 3., I-V curve for different polysilicon resistor

previously reported non-linear behavior of polysilicon resistor values [5]. Plots of four resistance values of polysilicon sources which give different $I-V$ characteristics are shown in the figure. For a 49 Kohm resistor, very little current flows at low biases. However, at approximately 1.75 volt, a large increase of current occurs. Again at about $2.1 \mathrm{~V}$ the increase in current is less in comparison to the range between 1.75 and $2.15 \mathrm{~V}$. We believe this sudden increase in current is due to thermal breakdown of polysilicon resistor [6]. The increase in resistance values beyond $2.1 \mathrm{~V}$ is 
similar (o) those of low resistance sources such as the 1.89 or 3.9 Kohm devices. The light emission occurs for to Kohm resistor at 2.25 Volt and the power required is $2.2 \mathrm{~mW}$. Though the $I-V$ eurve for hoth 1.89 or 3.9 Kohın are similar, the I-V curve for $5.7 \mathrm{Kohm}$ is different. Within the applied bias range, a nonlinear resistance change occurs for 5.7 Kohm resistor. We did not see any kink in I-V curve for 5.7 Kohm resistor which is seen for other resistors.

We have measured the power required for a particular radiation temperature for different resistance values. The results are shown in Fig. 4. Power required for light emission ofparticular

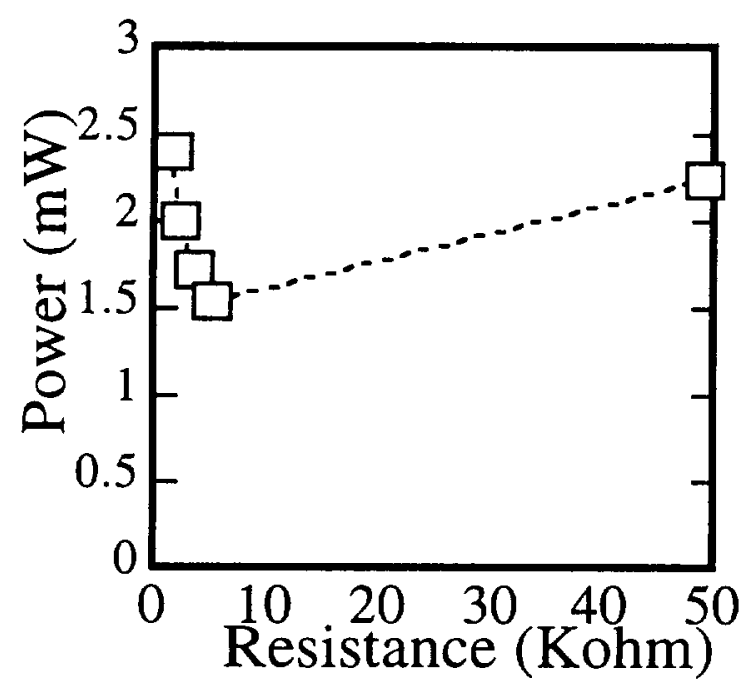

Figure 4, Power required for $1000 \mathrm{~K}$ radiation versus polysilicon resistance

temperature decreases with increase of resistance values. However, after attaining a minima, the required power increases. We believe the temperature of the sources are approximately 1100 $K$. The fact that the power requirement goes through a minima with increase in resistance values implies that more than one mechanism is responsible for light emission in polysilicon resistor. It has been reported that the change in resistance values beyond the kink point in Fig. 3 (from which light emission is observed) is due to current induced resistance decrease [7] and filamentation [8]. The optimum value of $5.7 \mathrm{Kohm}$ polysilicon resistance was chosen for the SIRTF project which requires minimum input power.

IV. Conclusions:

We have successfully designed and fabricated low power polysilicon sources for SIRTF flight project. Optimum polysilicon resistance value was chosen to achieve least power for IR radiation.

References:

[1] P.M. Alt, and P. Pleshko, Performance and design consideration of the thin film tungsten matrix display, IEEE Trans. electron devices, ED$20,1006,(1973)$

[2] G. Lamb, M. Jhabvala, and A. Burgess, Integrated circuit broadband infrared source, NASA Tech. briefs, 32, 1989

[3] H. Guckel ad D.W. Burns, Integrated transducer based on black body radiation from heated polysilicon films, Transducers, 85, 364, (1985)

[4] C.H. Mastrangelo, J.H. Yeh and R.S. Muller, Electrical and Optical characteristics of vacuum sealed polysilicon microlamps, IEEE Trans. Elect. Dev., ED-39, 1363, 1992

[5] Y.C. Tai, C.H. Mastrangelo and R.S. Muller , Thermal conductivity of heavily doped low pressure chemical vapor deposited polycrystaline silicon films, J. Appl. physics, 63, 1442, 1988

[6] H. Guckel and D.W. Burnes, Fabrication techniques for integrated sensor micro structure, IEDM Tech. digest, 176, 1986

[7] K. Kato, T. Ono and Y. Amemiya, A physical mechanism of current induced resistance decrease in heavily doped polysilicon resistors, IEEE Trans. Elect. Dev., ED-29, 1156, 1982

[8] D.W. Greve, Programming mechanism of polysilicon resistor fuses. IEEE Trans. Elect. Dev.. ED-29, 1156, (1982) 


\section{PUBLIC DOMAIN DECLARATION}

CAUTION: Export of technical data (information) with respect to the design, development, production, manufacture, assembly, operation, repair, testing, maintenance or modification of defense articles, i.e. all space flight hardware, ground tracking systems, launch vehicles to include sounding rockets and meteorological rockets, radiation hardened hardware and associated hardware and engineering units for listed items are controlled by the State Department, International Traffic in Arms Regulations (ITAR). Export of technical data(information) with respect to ground based sensors, detectors, National Security and Missile Technology items are controlled by the U.S. Commerce Department. Please contact the GSFC Export Control office if your export applies to the above or for further clarification of the U.S. State Department (ITAR) and the U.S. Department of Commerce Regulations. (Failure to comply with the ITAR regulations and/or the Commerce Department regulations may subject one to fines of up to $\$ 1$ million dollars and/or up to 10 years imprisonment per violation)

If your technical data does not apply with the above criteria, please select the numbered category below which best supports your declaration:

1. Public Domain - information which is published and which is generally accessible or available to the public

a. Through sales at news stands and bookstores;

b. Through subscriptions which are available without restriction to any individual who desires to obtain or purchase the published information;

c. Through second class mailing privileges granted by the U.S. government

d. At libraries open to the public or from which the public can obtain documents;

e. Through patents available at any patent office

f. Through unlimited distribution at a conference, meeting, seminar, trade show or exhibition, generally accessible to the public, in the United States, Through fundamental research in science and engineering at accredited institutions of higher learning in the U.S. where the resulting information is ordinarily published and shared broadly in the scientific community. Fundamental research is defined to mean basic and applied research in science and engineering where the resulting information is ordinarily published and shared broadly within the scientific community, as distinguished from research the results of which are restricted for proprietary reasons or specific U.S. Government access and dissemination controls. University research will not be considered fundamental research if:

(1) The University or its researchers accept other restrictions on publication of scientific and technical information resulting from the project or activity, or 
(2) The research is funded by the U.S. Government and specific access and dissemination controls protecting information resulting from the research are applicable.

h. Through public release (i.e., unlimited distribution in any form (e.g. not necessarily in published form) after approval by the cognizant U.S. government department and agency

i. Publicly Available Technology and Software- that technology and software that are already published or will be published; arise during, or result from fundamental research; are educational; or are included in certain patent applications (see 15 CFR 734)

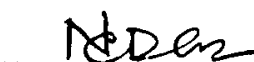

Signature

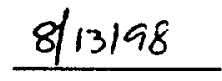

Date

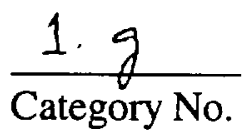

